\title{
GASTOS COM FUNÇÕES DE GOVERNO EM RELAÇÃO ÀS RECEITAS PRÓPRIAS E DE TRANSFERÊNCIAS DOS ESTADOS E UNIÃO NAS REGIÕES METROPOLITANAS DO SUDESTE DO BRASIL
}

\author{
EXPENSES FUNCTIONS OF GOVERNMENT IN RELATION TO OWN \\ RESOURCES AND TRANSFER OF STATES AND UNION IN THE \\ METROPOLITAN REGIONS OF SOUTHEASTERN BRAZIL
}

\section{Geovane Camilo Santos ${ }^{1}$}

\begin{abstract}
RESUMO: Esse artigo analisou a similaridade de comportamento dos gastos sociais com Assistência Social, Previdência Social, Saúde, Educação, Cultura, Urbanismo, Habitação e Saneamento em relação às receitas arrecadadas e recebidas de transferência de impostos, nas cidades das regiões metropolitanas do Sudeste brasileiro. Foram usadas pesquisas bibliográficas, documental, exploratória, descritiva, quantitativa e foi um estudo de caso. $\mathrm{Na}$ região metropolitana de São Paulo existiu similaridade nas funções: Habitação e Assistência Social - igualdade; nas funções Educação, Saúde, Urbanismo, Previdência Social, Cultura e Saneamento, houve oscilações com tendência a queda. Em Belo Horizonte existiu similaridade em todas as funções - redução de participação. Na região metropolitana do Rio de Janeiro houve igualdade em Urbanismo e Habitação e nas funções Assistência Social, Previdência Social, Saúde, Educação e Cultura tiveram redução da participação gastos/receitas. Na região metropolitana de Vitória as funções Assistência Social, Saúde, Educação, Cultura, Urbanismo, Habitação e Saneamento são similares - redução. No estudo por função averiguou comportamento similar para Assistência Social nas regiões de Rio de Janeiro, Belo Horizonte e Vitória (redução), para Previdência Social foi em São Paulo, Rio de Janeiro e Belo Horizonte (redução), Saúde, Educação e Cultura foram similares nas quatro regiões (redução), Urbanismo foi em São Paulo, Belo Horizonte e Vitória (diminuição), Saneamento foi similar para São Paulo, Belo Horizonte e Vitória (redução) e Habitação teve igualdade em São Paulo e Rio de Janeiro e redução em Belo Horizonte e Vitória. Logo, constatou que na maioria das cidades estudadas houve a predominância de diminuição dos gastos/receitas de impostos.
\end{abstract}

PALAVRAS-CHAVE: Gastos Sociais. Cidades Metropolitanas do Sudeste do Brasil. Funções Sociais. Receitas de Impostos.

ABSTRACT: This article analyzes the behavior of similarity of social spending on Social Welfare, Social Welfare, Health, Education, Culture, Urban Development, Housing and Sanitation in relation to collected and received tax transfer revenue, in the cities of the metropolitan areas of Southeastern Brazil . Were used bibliographical research, documentary, exploratory, descriptive, quantitative and it was a case study. In the metropolitan region of São Paulo existed similarity in functions: Housing and Social Assistance - equality; functions in Education, Health, Planning, Social Welfare, Culture and Sanitation, was prone to oscillations fall. In Belo Horizonte there was similarity in all functions - reducing participation. In the metropolitan area of Rio de Janeiro there was equality in Urbanisation and Housing and functions Social Welfare, Social Welfare, Health, Education and Culture had lower participation costs / revenues. In the metropolitan area of Victoria functions Social Welfare, Health, Education, Culture, Urban Development, Housing and Sanitation are similar

\footnotetext{
${ }^{1}$ Universidade Federal de Uberlândia. 
- reduction. In the study by function examined similar behavior for social assistance in the regions of Rio de Janeiro, Belo Horizonte and Vitória (reduction) for Social Security was in São Paulo, Rio de Janeiro and Belo Horizonte (reduction), health, education and culture were similar in the four regions (reduction), Urban was in São Paulo, Belo Horizonte and Vitória (decrease), Sanitation was similar to São Paulo, Belo Horizonte and Vitória (reduction) and Housing had equality in São Paulo and Rio de Janeiro and reduction in Belo Horizonte and Vitoria. Soon found that in most cities studied was the predominance of decrease in spending / tax revenues.

KEYWORDS: Social Spending. Metropolitan cities of southeastern Brazil. Social functions. Tax revenue.

\section{INTRODUÇÃO}

A União, os Estados e os Municípios são órgãos que possuem por função a prestação de bem-estar a população, cujo foco é o interesse coletivo e não individual ou de um pequeno grupo de pessoas. (SANTOS; ANDRADE, 2014).

Esses órgãos necessitam de recursos financeiros para a prestação desses serviços, sendo as principais fontes de financiamento as receitas arrecadadas por eles mediante os tributos e as transferências de outros órgãos públicos e/ou privados.

Os tributos são divididos em quatro formas: impostos, taxas, contribuições de melhorias e empréstimos compulsórios. As transferências são oriundas dos estados e da União, no primeiro caso são as participações dos seguintes impostos: Imposto sobre Circulação de Mercadorias e Prestação de Serviço de Transporte Interestadual, Intermunicipal e de Telecomunicação (ICMS), Imposto sobre Propriedade de Veículo Automotor (IPVA), IPI Exportação, Contribuições de Intervenções nos Domínios Econômicos (CIDEs). No segundo caso as cotas são dos seguintes impostos: Imposto de Renda (IR) e Imposto sobre Produtos Industrializados (IPI), mediante o Fundo de Participação dos Municípios (FPM) e as cotas do Imposto Territorial Rural (ITR) e Operações de Crédito, Câmbio e Seguro, ou Relativas a Títulos ou Valores Mobiliários (IOF ouro).

Segundo Slomski e Scarpin (2010) e Santos e Andrade (2014) as aplicações dos recursos arrecadados visam o bem-estar da população, e na teoria quanto maior for o gasto, melhor será o nível de bem-estar da população.

Os gastos sociais também são considerados gastos públicos, e de suma importância para o crescimento dos municípios. (SANTOS; ANDRADE, 2012). Esta forma de gasto está ligada a atender as demandas que estão atreladas diretamente ao dia a dia da população. 
O problema que gerou esse artigo foi: verificar se existe similaridade dos gastos sociais de Assistência Social, Previdência Social, Saúde, Educação, Cultura, Urbanismo, Habitação e Saneamento em relação às receitas arrecadadas e recebidas em transferências de impostos da União e dos Estados, nas regiões metropolitanas do Sudeste do Brasil, no período de 2008 a 2013 ?

O objetivo geral desse artigo foi analisar os gastos com Assistência Social, Previdência Social, Saúde, Educação, Cultura, Urbanismo, Habitação e Saneamento, nos últimos seis anos (2008-2013), confrontando com as receitas próprias e transferidas de impostos da (União e Estado), buscando a similaridade, nas cidades metropolitanas do sudeste do Brasil.

A justificativa desse trabalho é a geração de informação para o setor público, sendo que Santos e Andrade (2012) afirmam que a informação é importante para todos os setores, mas de forma especial para o setor público, pois permite avaliar a dimensão da aplicação dos recursos disponíveis, mesmo com informações inexpressivas sobre a gestão dos recursos nos municípios.

Logo, o estudo apresenta informações úteis à população, pois averigua a relação existente entre as receitas arrecadadas de impostos pelas cidades que compõe cada região metropolitana e as receitas de impostos transferidos pela União e pelos estados. Além disso, abordou a distribuição das receitas frente às despesas classificadas por funções de governo.

Ele também apresenta a possibilidade de geração de informações que serão usadas pelos gestores públicos para a elaboração, atendimento e acompanhamento de ações governamentais contidas no seu Plano de Governo.

O estudo é estruturado em cinco partes, sendo a primeira a presente introdução, seguida da revisão da literatura que apresenta aos leitores conceitos importantes sobre o trabalho. Após, encontra-se a metodologia, em que se apresentam os métodos para a elaboração do artigo, depois aparece os resultados da presente pesquisa e, por fim, têm as considerações finais.

\section{REVISÃO DA LITERATURA}

Segundo Santos e Andrade (2014) e Santos, Oliveira e Trajano Júnior (2013) as decisões que os entes públicos tomam são fundamentais, pois o dinheiro pertence à própria população, assim, ela tem o direito de saber como seu dinheiro é administrado. 
Os recursos despendidos em benefício à população devem proporcionar a ela o bom acesso à saúde, à educação, além de oferecer segurança pública eficiente, entre outros fatores.

As receitas públicas representam os ingressos às burlas e deve ocorrer monetariamente, sendo resultante do poder de tributar ou do agregado de bens e serviços a entidade pública. (BASTOS, 1997; HARADA, 2012; SECRETARIA DO TESOURO DA FAZENDA, 2006).

Logo, as receitas são os valores monetários que entram nos cofres públicos, mas todos os recursos não geradores de caixa não são classificados como receitas. As receitas são em virtude de leis, contratos, convênios e outros meios de títulos de origem específica.

As receitas que os entes públicos recebem são provenientes dos tributos, sendo obrigações pecuniárias e compulsórias. (BRASIL, 1966). Os tributos são classificados em quatro fatores: taxas, contribuições de melhoria, empréstimo compulsório e impostos.

As taxas são aquelas cobranças realizadas pelos entes públicos diretos e que possuem como fato gerador a contraprestação de serviço. (BRASIL, 1966). Para Paladini (2012) as taxas são as quantias obrigatoriamente paga em valores monetários em troca de algum serviço público.

A contribuição de melhoria é uma das espécies tributárias, surgidas na Inglaterra no início do ano de 1250 (BORGES JÚNIOR; MENDONÇA, 2010). Para Santos (1998) ela é um tributo em que incide sobre a valorização imobiliária, entretanto, segundo Paladini (2012), ela é pouquíssima usada pelo Poder Público.

Os empréstimos compulsórios são modelos de tributos de competência exclusiva da União, sendo restituíveis, e instituídos apenas por Lei Complementar, e serão usados nos casos de calamidades públicas, guerra externa ou investimento público urgente e relevante. (MAZZA, 2012). Segundo Marwell (2008) pelo fato dos empréstimos compulsórios serem restituíveis, muitas pessoas afirmam que ele não é tributo. Entretanto, esse assunto já foi alvo de muitas discussões e já ficou determinado pela Constituição Federal a sua caracterização como tributo.

Em conformidade a Boschetti e Salvado (2006) os impostos são aquelas arrecadações que os entes públicos realizam e que não está vinculada a contraprestação de serviço. Para Harada (2012) os impostos são classificados de duas formas: direta e indireta. A primeira forma é usada para o sujeito que praticou o ato que gerou o fato gerador, e esse é quem arcará com o ônus. A segunda forma é quando existe a transferência de ônus ao consumidor final, por meio da repercussão econômica. 
Em conformidade a Santos e Andrade (2014) os impostos arrecadados pelo município e os recebidos em transferências dos governos estaduais e federal constitui as fontes de recursos mais importantes dos municípios.

Os impostos municipais são: Imposto sobre Propriedade Predial e Territorial Urbana (IPTU); Imposto sobre Transmissão Inter Vivos, a qualquer título, por ato oneroso, de bens imóveis (ITBI); e Imposto sobre Serviços de Qualquer Natureza (ISSQN) (BRASIL, 1988).

O IPTU tem incidência sobre os bens imóveis, com a condição de que estejam no perímetro urbano do município. O ITBI tem incidência sobre os bens imóveis, porém é sobre a transferência, enquanto o IPTU é pela propriedade. E o ISSQN ou chamado propriamente de ISS incide sobre a prestação de serviços.

Segundo Nascimento (2006) as receitas que os municípios recebem em transferência possuem por objetivo atender os gastos de despesas correntes, satisfazendo as necessidades sociais. E Machado Junior e Reis (1996) acrescentam que essas referências são os ingressos provenientes de outras entidades, atendendo ou não a condições preestabelecidas.

De acordo com Santos e Andrade (2014) os principais recursos dos municípios são oriundos das transferências do Estado e da União, chamados de receitas transferidas, sendo a maior parte resultante dos impostos arrecadados por esses entes.

Em conformidade a Bovo (1995) a principal transferência recebida pelos municípios é mediante o Fundo de Participação dos Municípios (FPM), com a distribuição de recursos dos Impostos sobre Produtos Industrializados e Imposto de Renda. A Constituição Federal determinava a transferência do FPM em 22,5\%. (BRASIL, 1988). E a Emenda Constitucional $\mathrm{n}^{\mathrm{o}} 55$, de 2007, acrescentou mais $1 \%$, totalizando 23,5\%. (BRASIL, 2007).

Outra importante transferência recebida pelos municípios foi instituída em 1996, com a aprovação da Lei Complementar no 87 de 1996, que instituiu a desoneração do ICMS sobre as exportações, e após essa data, os Estados recebem as parcelas referentes aos coeficientes individuais de participação, inclusive com os valores dos municípios.

Os quatros estados do sudeste possuem os valores de distribuição do ICMS sobre exportação assim expressos: São Paulo 31,14180\%, estado com maior distribuição, em segundo lugar aparece outro estado do sudeste, Minas Gerais, com participação de 12,90414\%. O estado do Rio de Janeiro é o quinto com maior distribuição, 5,86503\% e o Espírito Santo, o sétimo em distribuição possui valor de 4,26332\%. (SEFAZ MT, 2014).

É importante frisar que a União transfere para os municípios 50\% do valor do Imposto sobre a Propriedade Territorial Rural, que estão situados neles (BRASIL, 1988). 
Nos municípios que existem a comercialização de ouro definido como ativo financeiro ou instrumento cambial auferem da União $70 \%$ do valor das Operações de Crédito, Câmbio e Seguro, ou Relativas a Títulos ou Valores Mobiliários (IOF) (BRASIL, 1988).

As mais importantes transferências recebidas dos Estados são oriundas da participação da arrecadação do ICMS, denominado Cota-Parte do ICMS.

Para Bovo (1995), os estados devem realizar a distribuição aos municípios de parte dos valores por eles arrecadados. Essa distribuição é relacionada pela variável do Valor Adicionado Fiscal (VAF). Entretanto, Soares, Gomes e Toledo Filho (2011) determinam que não é apenas o VAF, que existem também: população, área, mortalidade infantil, evasão escolar e, principalmente, o Valor Adicionado Fiscal (VAF).

Outra transferência realizada pelos estados aos municípios é a Cota-Parte do IPVA, com um percentual de 50\% dos valores arrecadados referentes ao Imposto sobre Propriedade de Veículos Automotores (IPVA). (BRASIL, 1988).

Os Estados recebem 10\% de transferência da União do IPI Exportação, desse valor $25 \%$ é repassado para os municípios, essa transferência é a Cota-Parte do IPI Exportação.

Os municípios recebem dos estados o valor percentual de 6,25\% sobre as Contribuições de Intervenções nos Domínios Econômicos (CIDEs). Esse valor é encontrado da seguinte equação: os estados recebem $25 \%$ da União e repassam $25 \%$ para os municípios, logo encontra que o repasse é de 6,25\% do valor total das CIDEs. Segundo Andrade e Santos (2014) esta transferência tem como característica a vinculação, pois visa financiar os programas de infraestrutura de transportes.

Os recursos que os municípios recebem de receitas, tanto próprias quanto as de transferências, são aplicados em benefício da população, “dona do dinheiro”, por meio das despesas de governo.

As despesas ou funções de governo foram instituídas pela Lei Federal $n^{\circ} 4.320$, de 1964, esta lei determinava nove funções. Com a criação da Portaria da Secretaria de Orçamento e Finanças (SOF) nº 09, de 1974, essas funções foram aumentadas para 16. E em 1999 ocorreu a aprovação pelo Ministério do Planejamento, Orçamento e Gestão (MPOG) no 42, que passou a determinar as funções sociais em 28 (SANTOS; ANDRADE, 2012).

Kohama (2001) define os gastos públicos como valores despendidos para a consecução de serviços públicos, necessários a atender o bem estar da população. Para Araújo, Monteiro e Cavalcante (2011) os gastos públicos são considerados os principais meios de atuação do governo, e é a principal maneira do governo expressar suas prioridades. 
Para Monteiro et al (2010) os gastos sociais ou públicos são aqueles que possuem a função alocativa, ou seja, é a provisão de bens e serviços para os cidadãos.

"Usualmente, consideram-se gastos sociais os dispêndios associados às áreas de previdência e assistência social, saúde, educação, moradia, habitação, saneamento básico, amparo ao empregado e, no contexto do Brasil, organização agrária.”. (MINISTÉRIO DA FAZENDA, 2003, p. 2).

Segundo Fernandes et al (1998) os gastos sociais são destinados à atender a melhoria das condições de vida da população. Sant'Anna (2006) e Souza, Oliveira Filho e Freitas (2011) os gastos sociais são aqueles realizados nas políticas públicas, destinadas a provisão de bens e serviços meritórios, sendo considerados semipúblicos: Assistência Social, Previdência Social, Saúde, Saneamento, Educação, Cultura, Urbanismo e Habitação.

Para Sposati (2007) muitos comentaristas de traço conservador e mesmo de ideologias esquerdistas caracterizam a Assistência Social como determinada área subordinada à ordem econômica, substituta do trabalho, e não como pertencente à ordem social, sendo uma afiançadora da defesa dos direitos próprios e da dignidade humana.

A Assistência Social é um direito do cidadão e dever do Estado, existindo uma política não contributiva, prevendo os mínimos sociais, por meio de um conjunto coeso de ações da iniciativa pública e da sociedade, para garantir o atendimento às necessidades básicas. (BRASIL, 1993). E Fernandes et al (1998) acrescentam que esses programas são focados no cuidado de crianças, adolescentes, idosos, reabilitação do profissional acidentado no trabalho e de dependentes do álcool e das drogas, presos e suas famílias.

A Previdência Social assegura a renda dos trabalhadores e de seus dependentes em casos de perda da capacidade de trabalho. Ela faz parte de ações do Estado e da sociedade, determinados pela CF, como Sistema de Seguridade Social. (RANGEL et al, 2009).

Os gastos com Previdência Social é como uma espécie de seguro, e é um direito do trabalhador e de sua família, expressos na Carta Magna, buscando ampará-los em situações de maternidade, doença, idade avançada, invalidez, reclusão e morte. (SILVA; MARTINS; COSTA, 2014).

Os gastos de Saúde são usados para controlar as doenças transmissíveis, para cobertura de gastos da vigilância sanitária, atendimento das mães e crianças, produção e distribuição de remédios gratuitamente, manutenção de hospitais de ensino e residência médica e assistência médica hospitalar, mediante o programa do Sistema Unificado de Saúde (SUS) (FERNANDES et al, 1998). 
Nesse sentido Backes et al (2008) e Scliar (2007) afirmam que a Saúde é um direito de toda a população, sendo o Estado responsável por tal função. O Estado deve oferecer condições justas e igualitárias de acesso aos serviços de promoção, proteção e recuperação da saúde. Isso deve ocorrer em todos os níveis, e para todos os habitantes do território nacional, direcionando a um desenvolvimento pleno do ser humano em sua individualidade.

Um dos problemas que afetam o meio ambiente é a falta de investimentos adequados em Saneamento Básico, sendo assim, um dos objetivos dessa função é assegurar um meio ambiente que favoreça a vida do ser humano e de outros seres, evitando a poluição da água, solo e ar (BOVOLATO, 2008).

Segundo a Organização Mundial da Saúde o Saneamento é o controle dos fatores que rodeiam o meio físico do homem e que exercem ou podem exercer alguma influência nociva sobre o bem estar físico, mental e social. (GUIMARÃES; CARVALHO; SILVA, 2007).

A Educação é uma prática social presente em momentos diferentes do espaço e da produção da vida social. (CALEJJA, 2008; DOURADO; OLIVEIRA; SANTOS, 2007). E Jacob, Hees e Waniez (2014) afirmam que a educação desempenha um papel precípuo na mobilidade social, sendo um dos fatores possíveis para a formação profissional e existir uma melhor condição de vida.

Os gastos com Educação pertencem à formulação política setorial e manutenções para expansão e melhorias de escolas, museus, bibliotecas estabelecimento de educação física (FERNANDES et al, 1998). Jacob, Hees e Waniez (2014) apresentam que são quatro aspectos importantes para medir a educação de uma região: acesso à escola, alfabetização, níveis de educação e a importância das escolas particulares.

Para Canedo (2009) a Cultura exerce papel central na vida da sociedade contemporânea exigindo a intervenção efetiva dos poderes públicos mediante a implantação de órgãos específicos para a gestão cultural em todas as esferas públicas e na elaboração e execução de políticas públicas.

Para Fernandes et al (1998) os gastos com Cultura visam promover o conhecimento de estabelecimentos culturais, e defende a recuperação do patrimônio histórico e artístico.

A Habitação é um dos cinco serviços públicos essenciais à população, juntamente com: educação, saúde, seguridade social e serviços sociais pessoais. A Habitação se relaciona com uma concepção do estado de bem-estar social, sendo que seu status como política pública se consolidou ao longo do século XX. (MALPASS, 2004). 
Em conformidade a Agache (1931) o Urbanismo é o conjunto de regras, para serem aplicadas ao melhoramento das edificações, arruamento, circulação e do descongestionamento das artérias públicas.

Segundo Fernandes et al (1998) tanto os gastos com Urbanismo quanto Habitação podem ser usados os recursos do FGTS, sendo para construção e manutenção de residências destinadas ao uso de servidores públicos civis ou militares.

\section{METODOLOGIA}

O presente estudo fez uso das seguintes pesquisas: bibliográficas e documental para os procedimentos, essas duas formas de pesquisas foram usadas para fazer o levantamento dos assuntos estudados e para coletar os dados.

As pesquisas exploratórias e descritivas foram usadas para os objetivos. Quanto à abordagem usou pesquisa quantitativa e ainda se caracterizou como um estudo de caso.

Os dados para a consecução do presente estudo foram extraídos do site Finanças do Brasil (FINBRA) em: <https://www.tesouro.fazenda.gov.br/pt/prefeituras-governosestaduais/sobre>.

Após levantamento, os dados foram trabalhados em planilhas do software Excel 2007, permitindo totalizar os valores das variáveis a serem analisadas.

Foi realizada a escolha do sudeste do Brasil, por ser a região mais rica do país (IBGE, 2014), sendo que nessa região existem 4 estados e consequentemente 4 região metropolitanas: São Paulo, Belo Horizonte, Rio de Janeiro e Vitória.

A região metropolitana de São Paulo possui 39 municípios, sendo eles: Arujá, Barueri, Biritiba-Mirim, Caieiras, Cajamar, Carapicuíba, Cotia, Diadema, Embu, Embu-Guaçu, Ferraz de Vasconcelos, Francisco Morato, Franco da Rocha, Guararema, Guarulhos, Itapecerica da Serra, Itapevi, Itaquaquecetuba, Jandira, Juquitiba, Mairiporã, Mauá, Mogi das Cruzes, Osasco, Pirapora do Bom Jesus, Poá, Ribeirão Pires, Rio Grande da Serra, Salesópolis, Santa Isabel, Santana de Parnaíba, Santo André, São Bernardo do Campo, São Caetano do Sul, São Lourenço da Serra, São Paulo (que é o município-sede), Suzano, Taboão da Serra e Vargem Grande Paulista.

A região metropolitana de Belo Horizonte possui 34 municípios, sendo eles: Baldim, Belo Horizonte, Betim, Brumadinho, Caeté, Capim Branco, Confins, Contagem, Esmeraldas, Florestal, Ibirité, Igarapé, Itaguara, Itatiaiuçu, Jaboticatubas, Juatuba, Lagoa Santa, Mário 
Campos, Mateus Leme, Matozinhos, Nova Lima, Nova União, Pedro Leopoldo, Raposos, Ribeirão das Neves, Rio Acima, Rio Manso, Sabará, Santa Luzia, São Joaquim de Bicas, São José da Lapa, Sarzedo, Taquaraçu de Minas e Vespasiano.

A região metropolitana do Rio de Janeiro é composta por 18 municípios: Belford Roxo, Duque de Caxias, Guapimirim, Itaboraí, Itaguaí, Japeri, Magé, Mesquita, Nilópolis, Niterói, Nova Iguaçu, Paracambi, Queimados, Rio de Janeiro, São Gonçalo, São João de Meriti, Seropédica e Tanguá.

E a região metropolitana de Vitória têm 7 municípios: Cariacica, Fundão, Guarapari, Serra, Viana, Vila Velha e Vitória.

\section{RESULTADOS}

Os resultados encontrados na presente pesquisa foram apresentados em gráficos. A apresentação começou pela região metropolitana de São Paulo, seguida de Belo Horizonte, após Rio de Janeiro e por fim Vitória. Essa ordem de sequência foi a relação ao número de cidades que compõe a região.

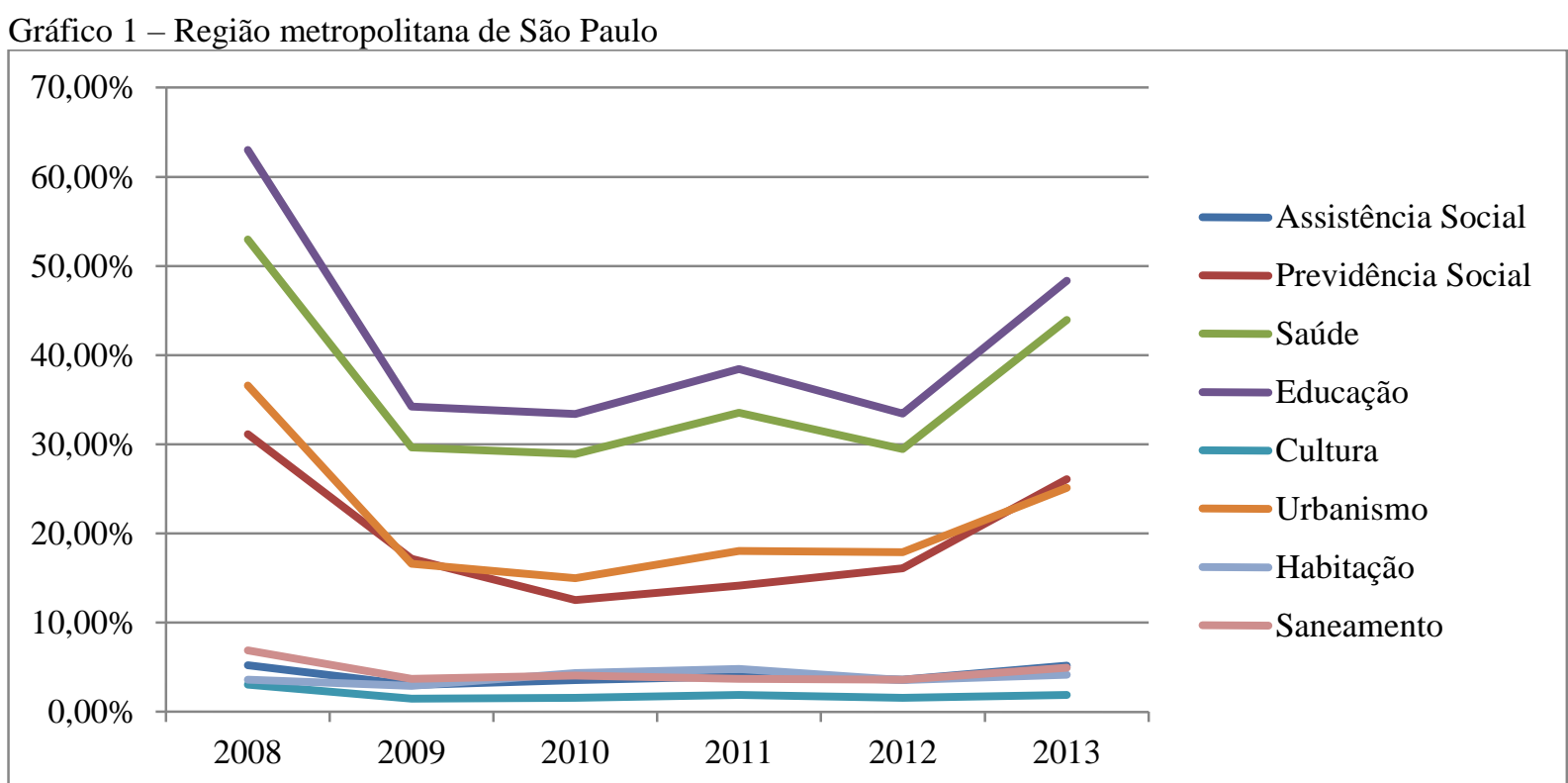

Fonte: Elaborado pelo autor

Os resultados apresentados no Gráfico 1, da região metropolitana de São Paulo, apresenta que as funções, Habitação e Assistência Social possuem comportamentos similares, uma vez que os resultados foram iguais para o valor inicial e final, no lapso temporal. 
As funções Educação, Saúde, Urbanismo, Previdência Social, Cultura e Saneamento também são parecidas, pois possuem quedas no início do período analisado, porém com o tempo elas vão oscilando entre aumentos e quedas e fecha com o último período com tendências ao crescimento.

Vale frisar, que nessas últimas 6 funções ocorreu redução dos valores gastos com elas em relação aos impostos arrecadados e recebidos em transferências ao início do período estudado, ou seja, os valores gastos com elas foram inferiores que ao início do período estudado.

Logo, é preciso realizar uma observação se essas cidades estão realmente cumprido todas as suas obrigações sociais para com a população com menos recurso o que é recomendado, ou se ela está deixando de prestar o bem-estar a população, o que causa sérios danos ao povo.

Gráfico 2 - Região metropolitana de Belo Horizonte

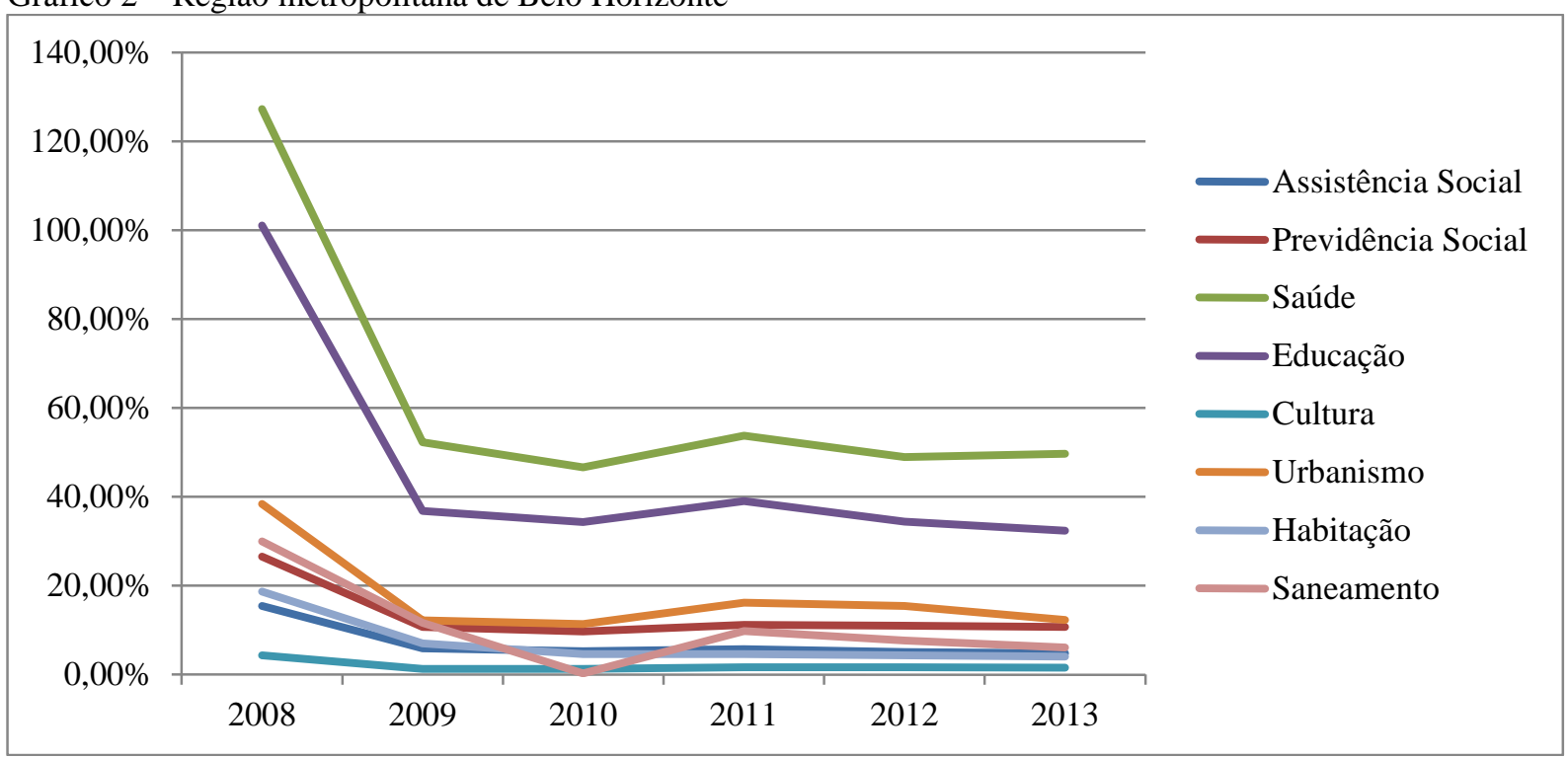

Fonte: Elaborado pelo autor

O Gráfico 2 expressa os resultados da região metropolitana de Belo Horizonte, sendo possível averiguar que o comportamento das 8 funções são similares na comparação entre o primeiro e o último ano, pois todas apresentaram redução de gastos em relação as receitas.

As funções com maiores reduções foram Saúde e Educação, que caíram mais da metade entre o primeiro e último ano estudado.

$\mathrm{Na}$ cidade metropolitana de Belo Horizonte, como acontece com a cidade metropolitana de São Paulo, precisa realizar uma análise mais aprofundada, com a finalidade 
de averiguar se houve eficácia dos gestores, se todas as obras foram realizadas ou se houve economia de gastos, entretanto, afetando o bem estar da população.

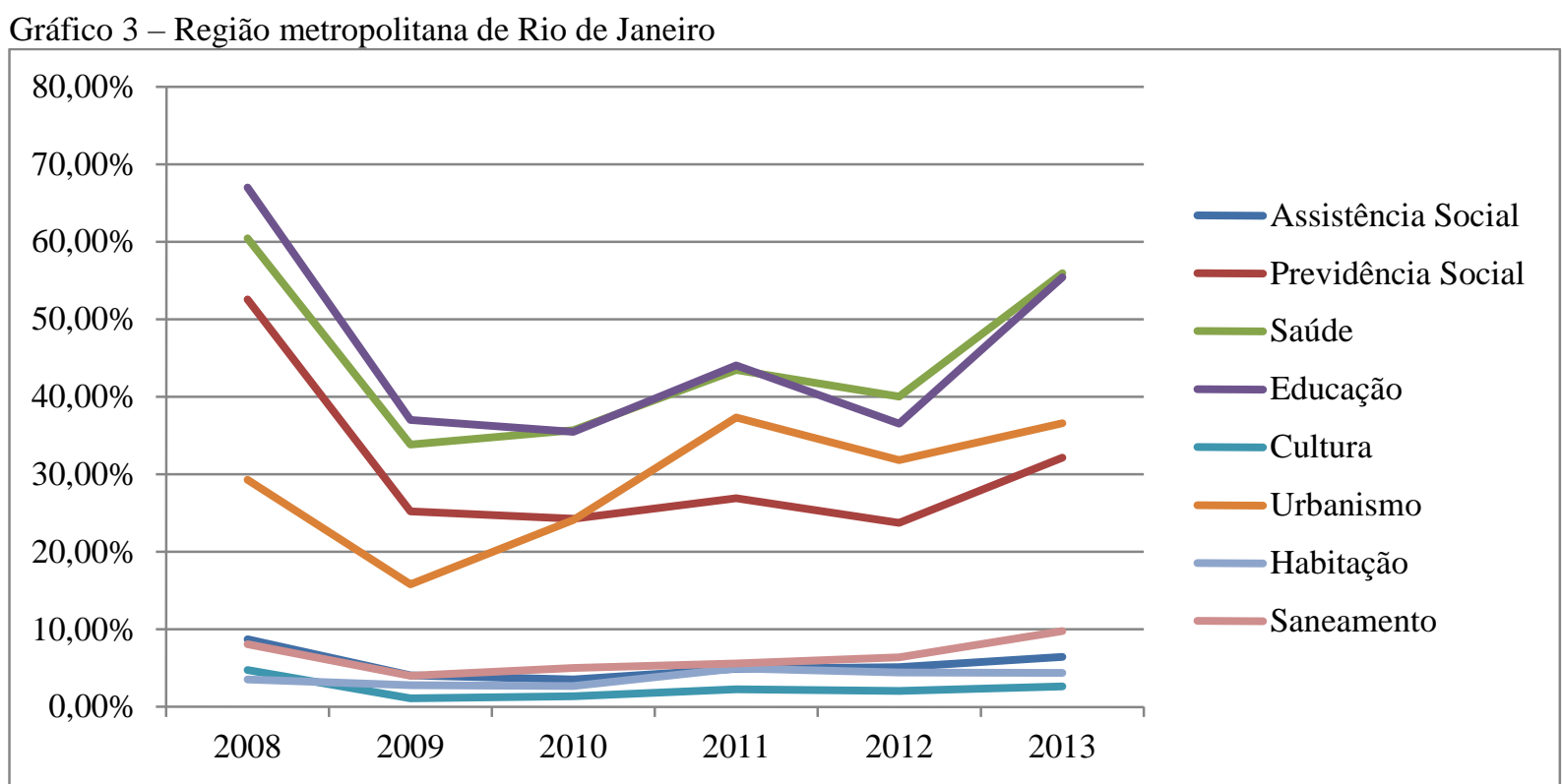

Fonte: Elaborado pelo autor

Nas funções sociais das cidades metropolitanas do Rio de Janeiro foram constatados similaridades nas funções: Urbanismo e Habitação, com a predominância de aumento do último para o primeiro ano estudado.

As funções Assistência Social, Previdência Social, Saúde, Educação e Cultura foram constatados comportamentos similares, sendo caracterizado pela redução da percentagem de participação das despesas frente às receitas, na análise do primeiro para o último ano analisado.

E a função Habitação foi a única a não ter comportamento similar com nenhuma outra função, uma vez que o valor que ela possuía em 2008 foi igual ao valor de 2013.

Gráfico 4 - Região metropolitana de Vitória 


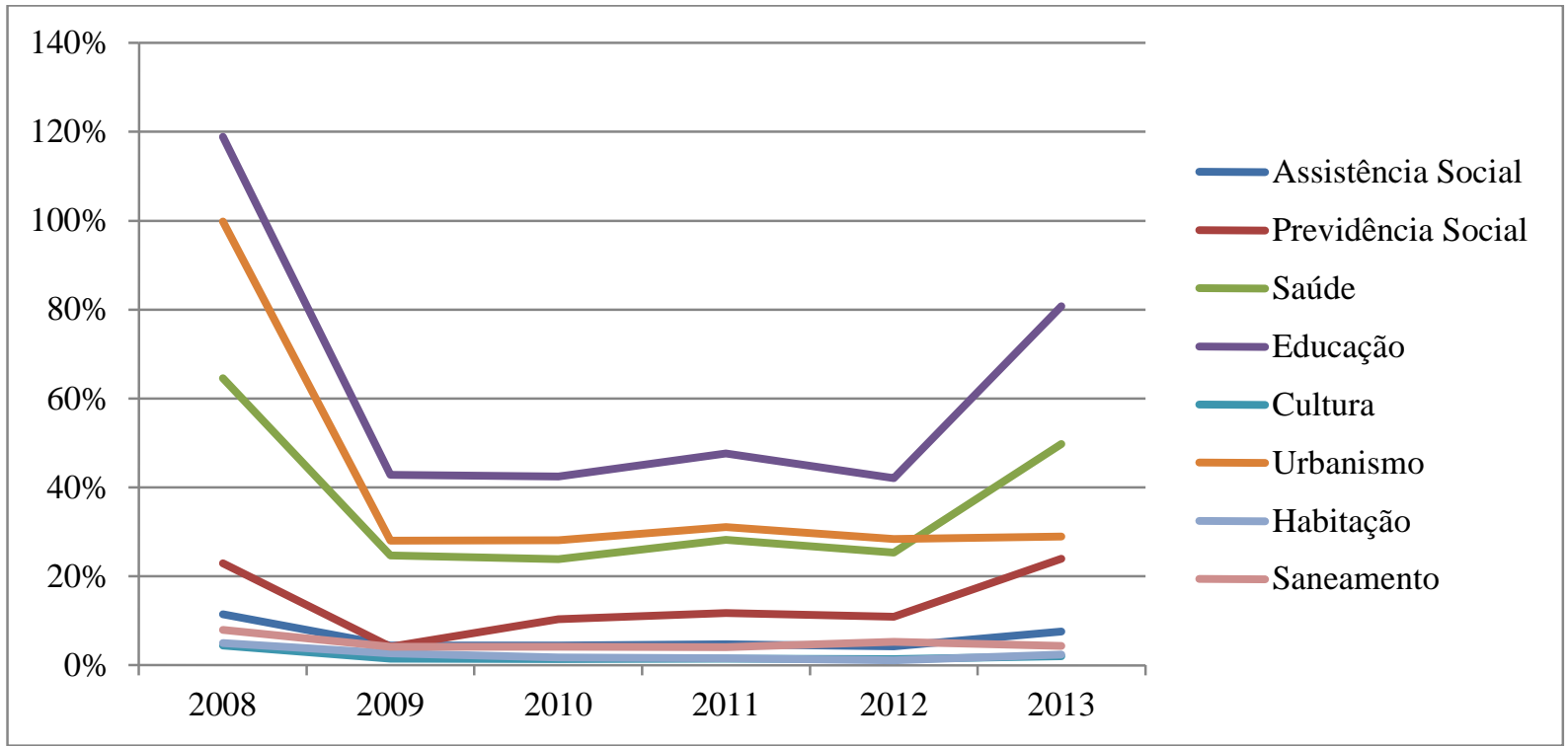

Fonte: Elaborado pelo autor

E nas cidades que compõe a região metropolitana de Vitória constatou comportamentos parecidos para as funções: Assistência Social, Saúde, Educação, Cultura, Urbanismo, Habitação e Saneamento que demonstraram redução da participação das despesas frente às receitas arrecadadas e transferidas.

A função Previdência Social, apresentou comportamento divergente das demais funções dessa região, uma vez que foi averiguado crescimento da participação das despesas em relação às receitas arrecadadas e transferidas.

Após analisar o comportamento das funções por região metropolitana, faz-se uma análise, buscando a similaridade das mesmas funções entre as regiões metropolitanas.

Gráfico 5 - Relação entre a Arrecadação de impostos com a função Assistência Social

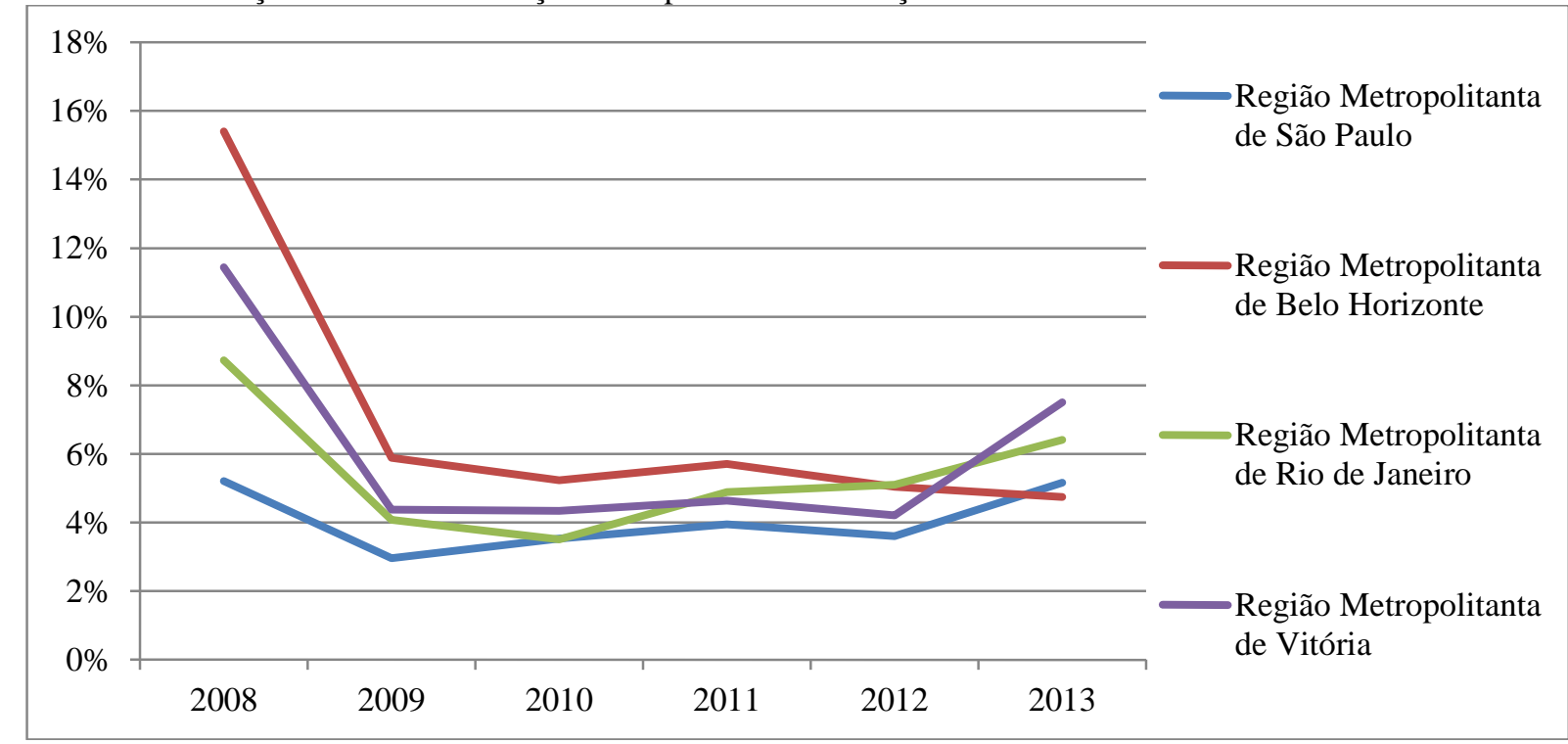

Volume 4, Número 8

Ago./Dez. 2015

Revista UNEMAT de Contabilidade

ISSN: 2316-8072 
A função Assistência Social apresentou comportamento similar na primeira comparação de períodos (2008/2009), para as regiões metropolitanas de Belo Horizonte, Rio de Janeiro e Vitória, sendo que a característica foi a redução da participação das despesas frente às receitas transferidas e arrecadadas.

$\mathrm{Na}$ comparação do último período averigua que entre essas três cidades metropolitanas, Rio de Janeiro e Vitória apresentaram similaridade, sendo tendência ao crescimento.

E na comparação entre o primeiro e o último ano (2008/2013) constatou que houve similaridade entre as cidades metropolitanas de Rio de Janeiro, Belo Horizonte e Vitória, que tiveram quedas de gastos nessa função. E em São Paulo averiguou que o valor ao final do período foi igual ao valor no início do período.

Esses valores podem ser suplementados por Fernandes et al (1998), que afirmam serem usados esses recursos para cobrirem gastos com tratamento de álcool e drogas, com os presos e suas famílias.

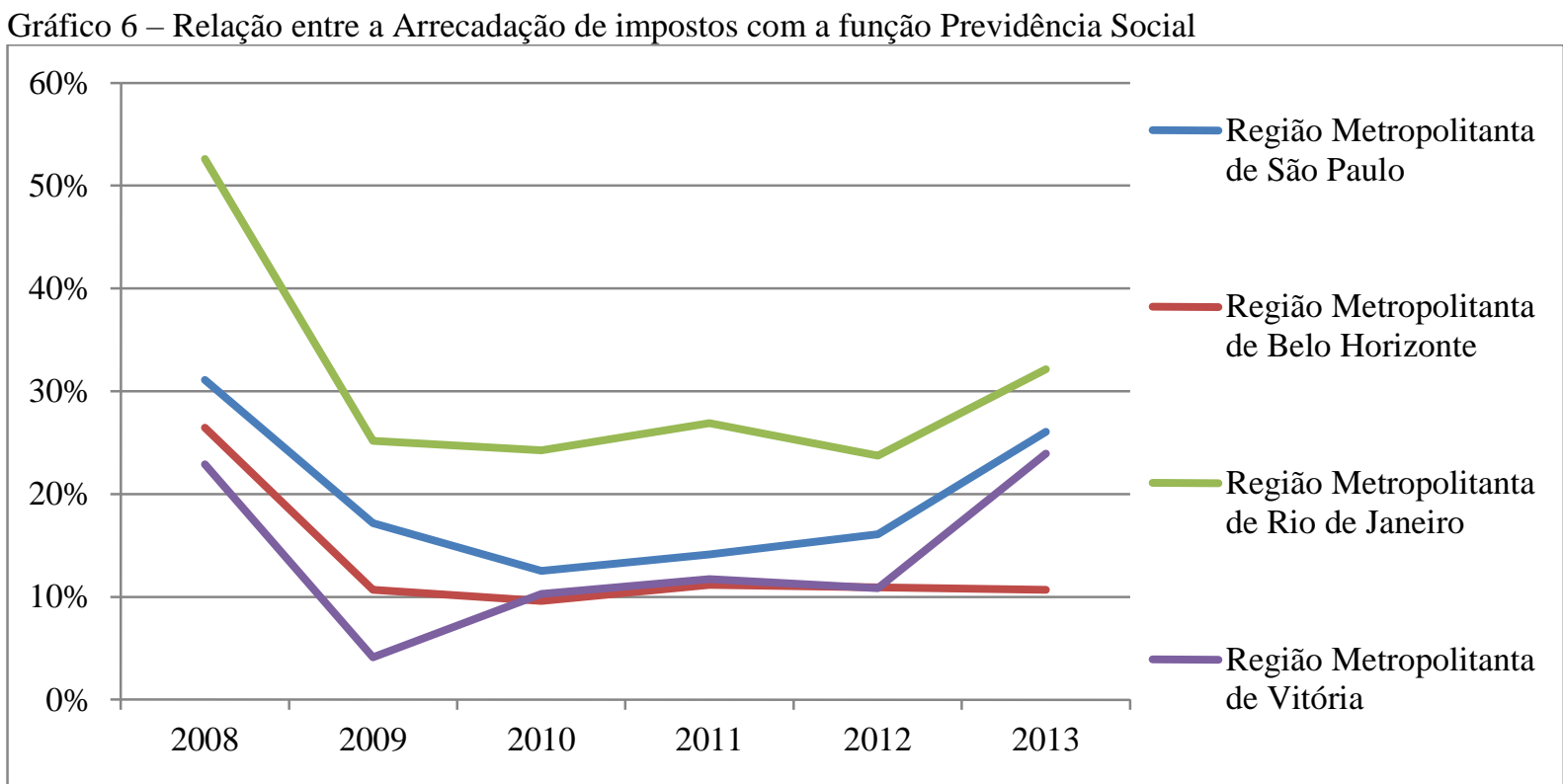

Fonte: Elaborado pelo autor

A função Previdência Social demonstrou similaridade para as regiões metropolitanas de São Paulo, Belo Horizonte, Rio de Janeiro e Vitória, no início do período analisado, tendo como ponto de equidade a redução dos valores gastos com as despesas frente às receitas arrecadadas e transferidas. 
No final do período averigua que as regiões metropolitanas de São Paulo, Rio de Janeiro e Vitória apresentaram tendências de crescimentos. Na região metropolitana de Vitória foi constatado aumento dessa função, ou seja, as prefeituras dessas cidades gastaram percentual maior no último ano em comparação ao primeiro.

E a comparação entre 2008/2013 constatou que nas cidades metropolitanas de Rio de Janeiro, São Paulo e Minas Gerais tiveram reduções dos gastos em comparação as receitas recebidas de transferências e arrecadadas com impostos.

Esses resultados podem ser justificados, pelo aumento do número de idosos na região e consequentemente o aumento da necessidade de gastos nessa função. (FERNANDES et al, 1998; IBGE, 2010).

Gráfico 7 - Relação entre a Arrecadação de impostos com a função Saúde

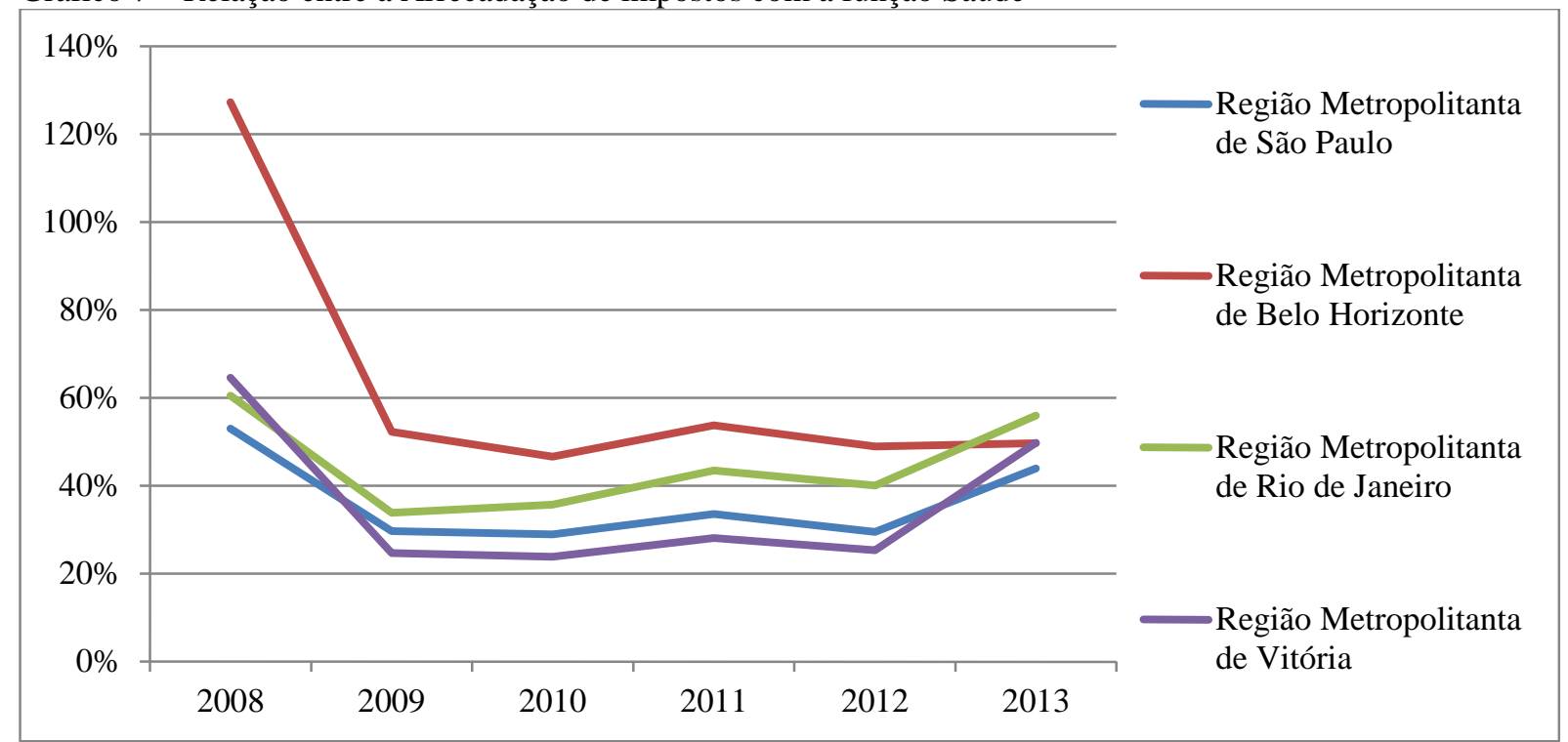

Fonte: Elaborado pelo autor

Na função Saúde averiguou que o comportamento similar foi encontrado nas quatro regiões metropolitanas, com a característica de ser a redução da relação despesas/receitas arrecadadas e transferidas, fato encontrado no início do lapso temporal estudado.

Ao final do lapso temporal averigua comportamento similar entre as regiões de São Paulo, Rio de Janeiro e Vitória, cuja característica foi o aumento da relação entre despesa com Saúde e as receitas arrecadadas e transferidas com impostos.

E na comparação entre o primeiro e o último período verificou similaridade nas regiões de São Paulo, Rio de Janeiro e Vitória, sendo essa a estabilidade, ou seja, a relação 
entre receitas arrecadadas e transferidas de impostos versos gastos sociais com Saúde, existente em 2008 foi similar com a relação encontrada em 2013.

A região de Belo Horizonte teve uma redução superior a $50 \%$, esse fato pode ser preocupante, pois é provável que os governos municipais das cidades que compõe a região metropolitana de Belo Horizonte não deve ter conseguido ofertar um bem estar a população, mas é preciso um estudo qualitativo para poder se afirmar isso com certeza. Entretanto, se o governo tiver conseguido fazer tal oferta, isso demonstra que ele foi eficiente e eficaz, sendo preciso que outras regiões busquem conhecer quais foram as estratégias adotadas por essa região.

Gráfico 8 - Relação entre a Arrecadação de impostos com a função Educação

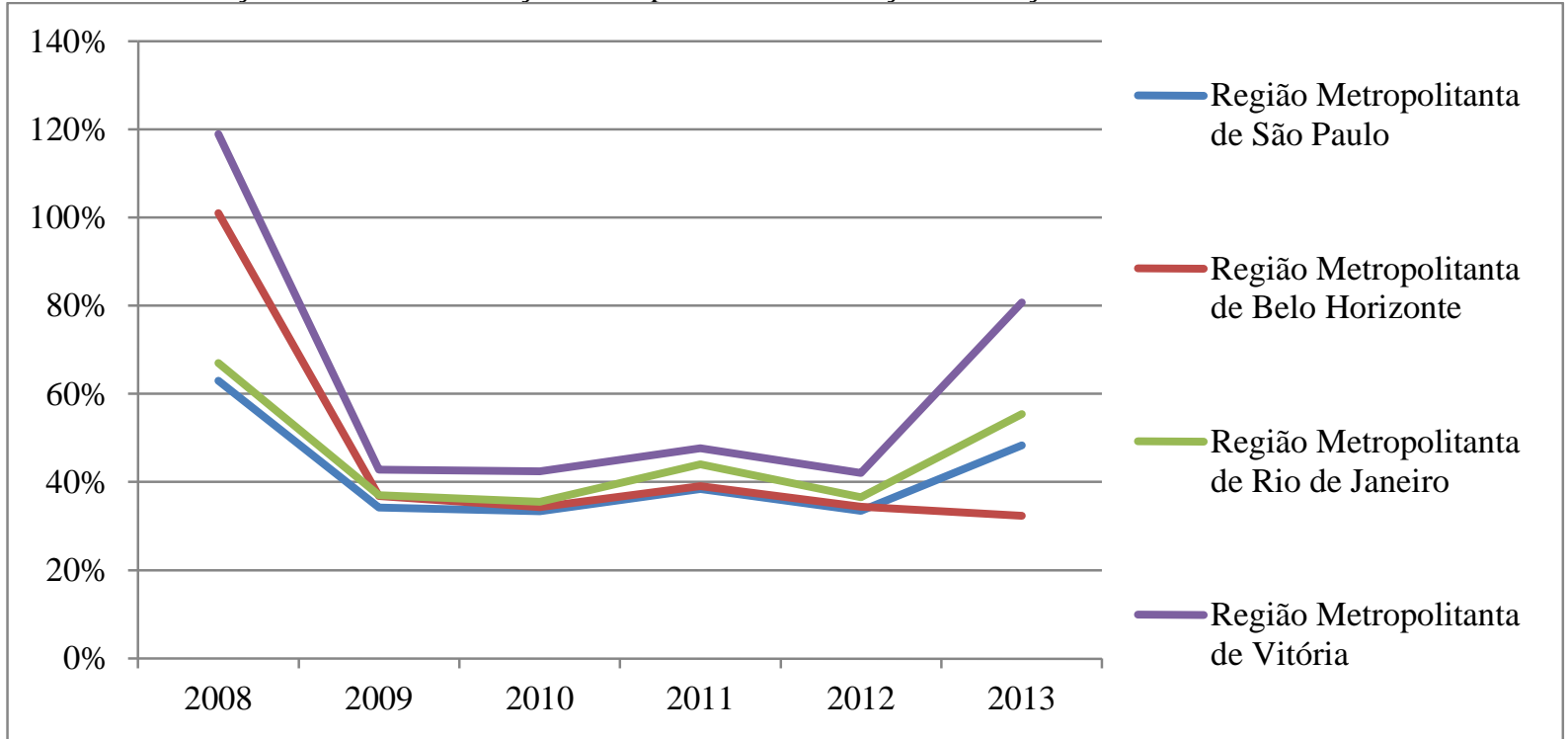

Fonte: Elaborado pelo autor

A função Educação demonstra similaridade de comportamento nas quatro regiões metropolitanas do sudeste brasileiro, no início do lapso estudado, sendo essa a redução de valores das despesas frente às receitas arrecadadas e transferidas por essas cidades.

No último período estudado constatou que as regiões de São Paulo, Rio de Janeiro e Vitória apresentaram crescimento dos gastos com essa função em relação aos valores arrecadados e recebidos com impostos.

E na comparação direta entre 2008 e 2013 averiguou similaridade nas regiões metropolitanas de São Paulo, Rio de Janeiro e Vitória, sendo essa a redução da relação entre receitas arrecadadas e recebidas de transferências de impostos. 
Jacob, Hees e Waniez (2014) estudaram a região metropolitana de Rio de Janeiro, sendo que eles encontraram em seus estudos que 6,6\% das pessoas dessa região metropolitana nunca frequentaram uma escola e o IBGE (2010) apresenta que a região metropolitana de Belo Horizonte têm uma percentagem de 6,9\%, São Paulo de 7,0\%, sendo esse índice bom se comparamos com a média nacional, que é de 9,8\%, no sudeste apenas a região metropolitana de Vitória apresenta valor acima da média nacional, sendo de 11,2\%.

No tangente as pessoas serem alfabetizadas (considera a pessoa conseguir ler e escrever um bilhete), Jacob, Hees e Waniez (2014) encontraram que na região metropolitana de Rio de Janeiro, 95,1\% das pessoas são alfabetizadas, sendo esse índice superior a média nacional, que é de $89,5 \%$.

Ao analisarem o nível de pessoas que frequentaram ou frequentam o ensino superior, constatou um percentual de $18,3 \%$, se esse valor for comparada a média nacional será considerado alto, uma vez que apenas $8,31 \%$ da população possui ensino superior (IBGE, 2010; JACOB; HEES; WANIEZ, 2014).

E na relação dos alunos que frequentam escolas privadas se encontra um valor de $36,4 \%$, sendo esse índice alto ao comparar a média nacional que é de $21,9 \%$, ou seja, quase 2 vezes mais é a proporção de alunos que cursam o ensino em escola privada na região metropolitana do Rio de Janeiro em comparação com a média nacional. (JACOB; HEES; WANIEZ, 2014).

A região metropolitana de Belo Horizonte teve uma queda de praticamente $200 \%$ na função Educação, isso reflete que os gestores públicos diminuíram os gastos com essa função em comparação com as receitas de impostos (arrecadadas e recebidas de transferências), com esse fato é preciso analisar se foi uma boa administração, ou se foi falta de investimentos em uma função tão importante para o crescimento do país.

As funções Educação e Saúde tiveram as maiores participações em relação ao total de receitas, esse fato se justifica pelas determinações constitucionais, que instituem a aplicação de no mínimo 25\% para a Educação e 15\% para a Saúde do total da arrecadação dos impostos municipais, incluindo-se as transferências dos entes estadual e federal que tenham como fonte a arrecadação de impostos. (BRASIL, 1988).

Porém um fato é preocupante, pois essas duas funções apresentam redução de participação frente ao total de receitas arrecadadas e transferidas pelo Estado e União, e de modo especial essa preocupação se atenua nas cidades que compõem a região metropolitana de Belo Horizonte. 


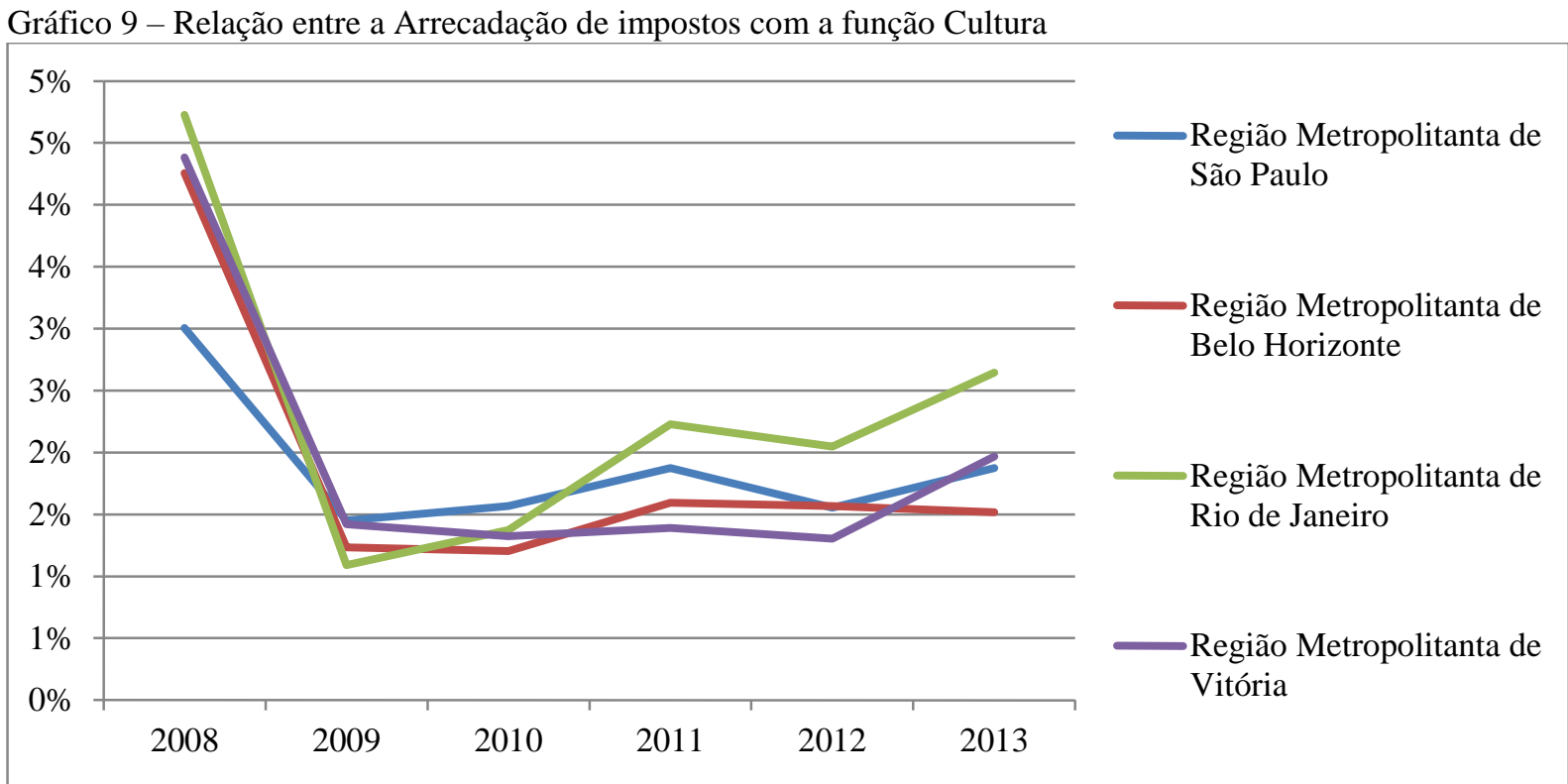

Fonte: Elaborado pelo autor

$\mathrm{Na}$ função Cultura constatou comportamento similar para todas as regiões metropolitana estudadas, no início do lapso temporal, possuindo como característica a redução na relação despesas/receitas arrecadadas e transferidas.

No final do período estudado constatou que houve similaridade nas regiões metropolitanas de São Paulo, Rio de Janeiro e Vitória, cuja característica foi tendência ao crescimento.

E na relação 2008/2013 averiguou comportamento similar em todas as regiões metropolitanas do sudeste brasileiro, uma vez que ambos apresentaram retração.

Gráfico 10 - Relação entre a Arrecadação de impostos com a função Urbanismo 


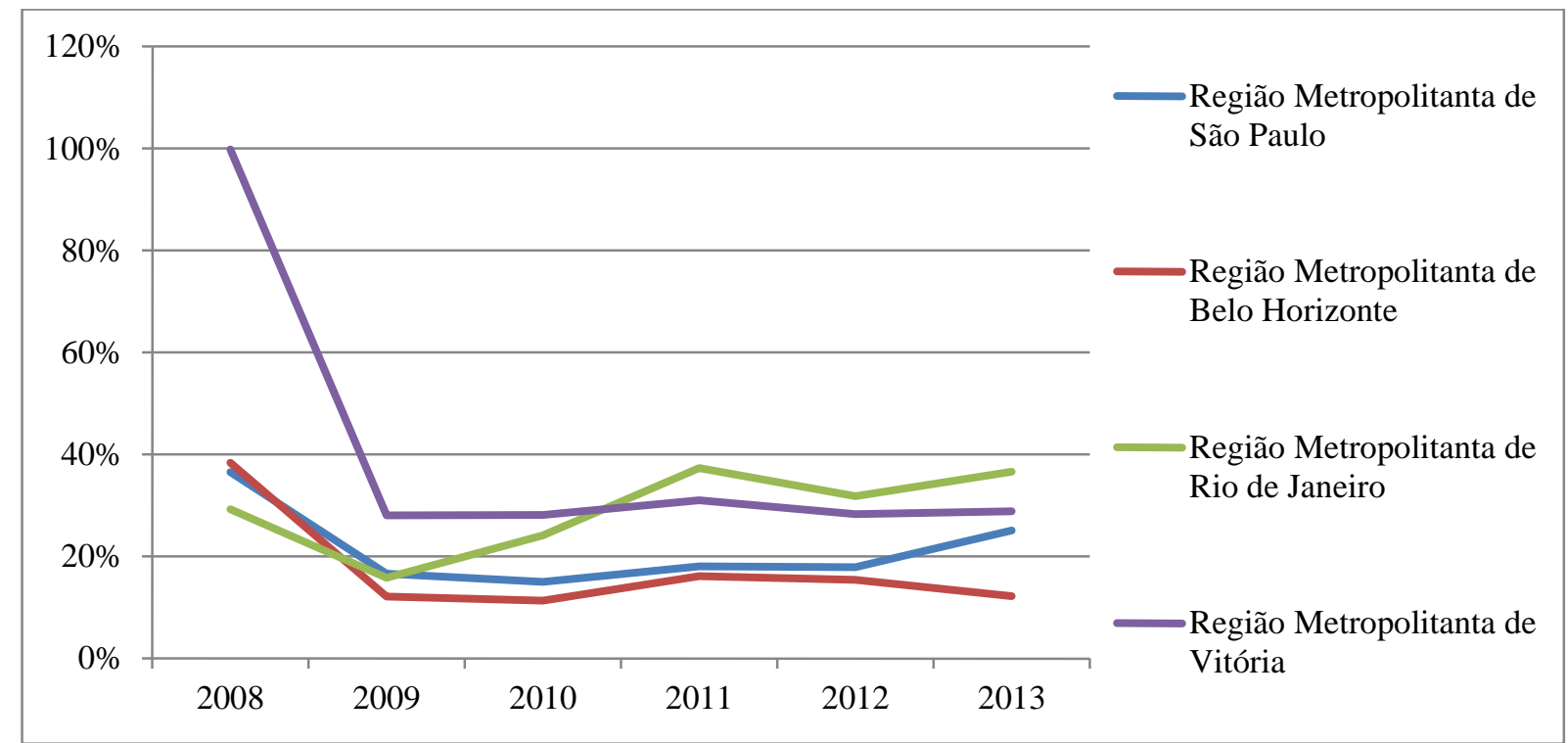

Fonte: Elaborado pelo autor

A função Urbanismo demonstrou comportamento similar nas regiões metropolitana de São Paulo, Belo Horizonte e Vitória, ao começo do lapso temporal, com a característica de diminuição de participação das despesas frente às receitas arrecadadas e transferidas.

Nas regiões metropolitanas de São Paulo, Rio de Janeiro e Vitória foi constatado similaridade, ao final do período, cuja caraterística foi tendência ao crescimento.

E na relação entre 2008 e 2013 averiguou comportamento similar entre as regiões metropolitanas de Belo Horizonte, São Paulo e Vitória, tendo como característica a redução da participação do gasto social com Urbanismo em relação às receitas arrecadadas e recebidas de transferências de impostos. A região metropolitana de Rio de Janeiro apresentou aspecto divergente das demais, uma vez que ela apresentou crescimento da relação gasto social/receitas.

Gráfico 11- Relação entre a Arrecadação de impostos com a função Habitação 


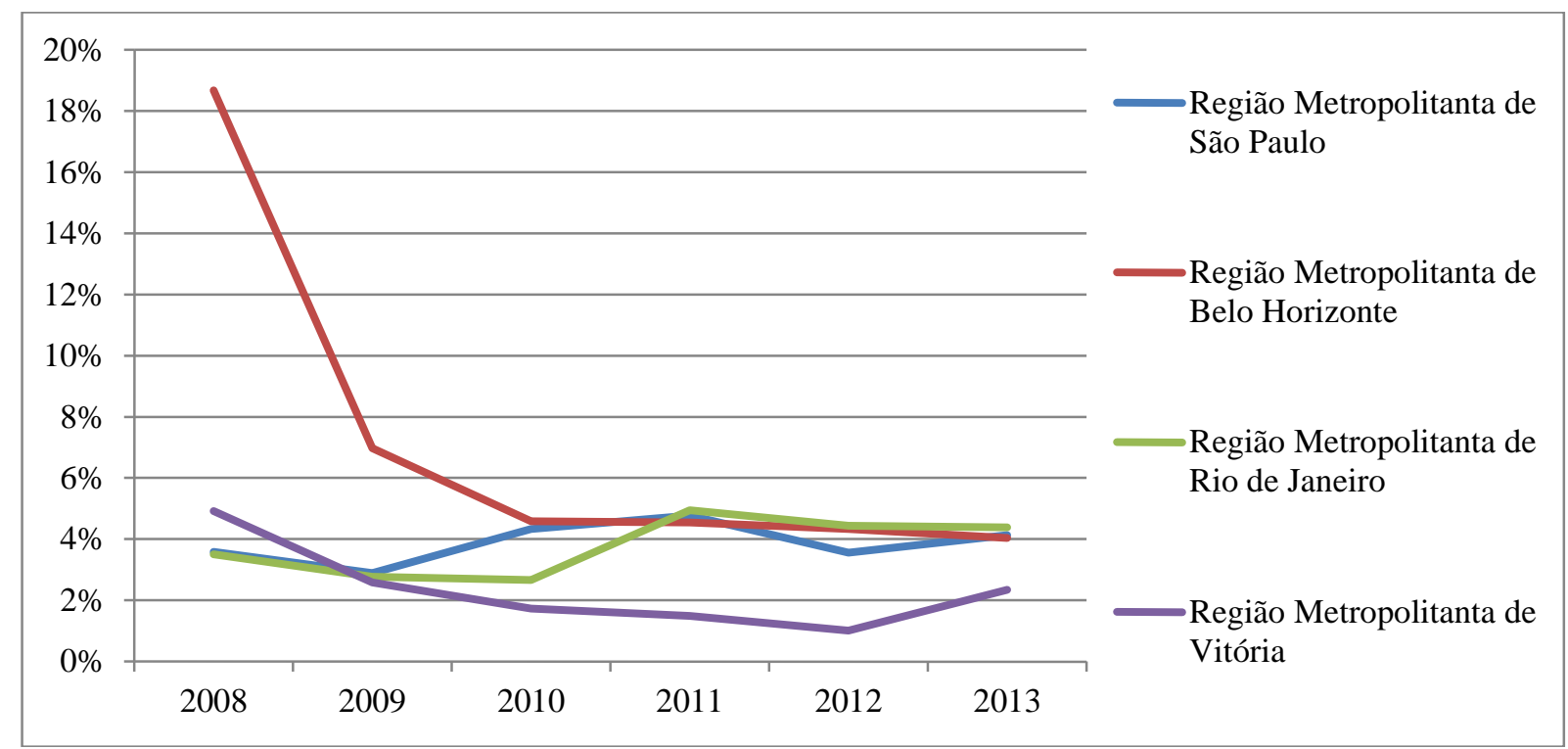

Fonte: Elaborado pelo autor

Na função Habitação existe similaridade para as regiões metropolitana de São Paulo, Rio de Janeiro, Belo Horizonte e Vitória, ao princípio do período em estudo, cuja característica foi a redução.

Ao final do período estudado constatou similaridade entre as regiões de Belo Horizonte e Rio de Janeiro, cuja característica foi a estabilidade. Houve também similaridade das regiões metropolitanas de São Paulo e Vitória que tiveram tendência ao crescimento.

E na comparação entre o primeiro período estudado e o último apurou a ocorrência de duas similaridades: a primeira ficou com as regiões de Belo Horizonte e Vitória que apresentaram redução da relação gasto social/receita, a segunda foi encontrada nas regiões metropolitanas de São Paulo e Rio de Janeiro, cuja característica foi tendência ao crescimento.

Gráfico 12 - Relação entre a Arrecadação de impostos com a função Saneamento 


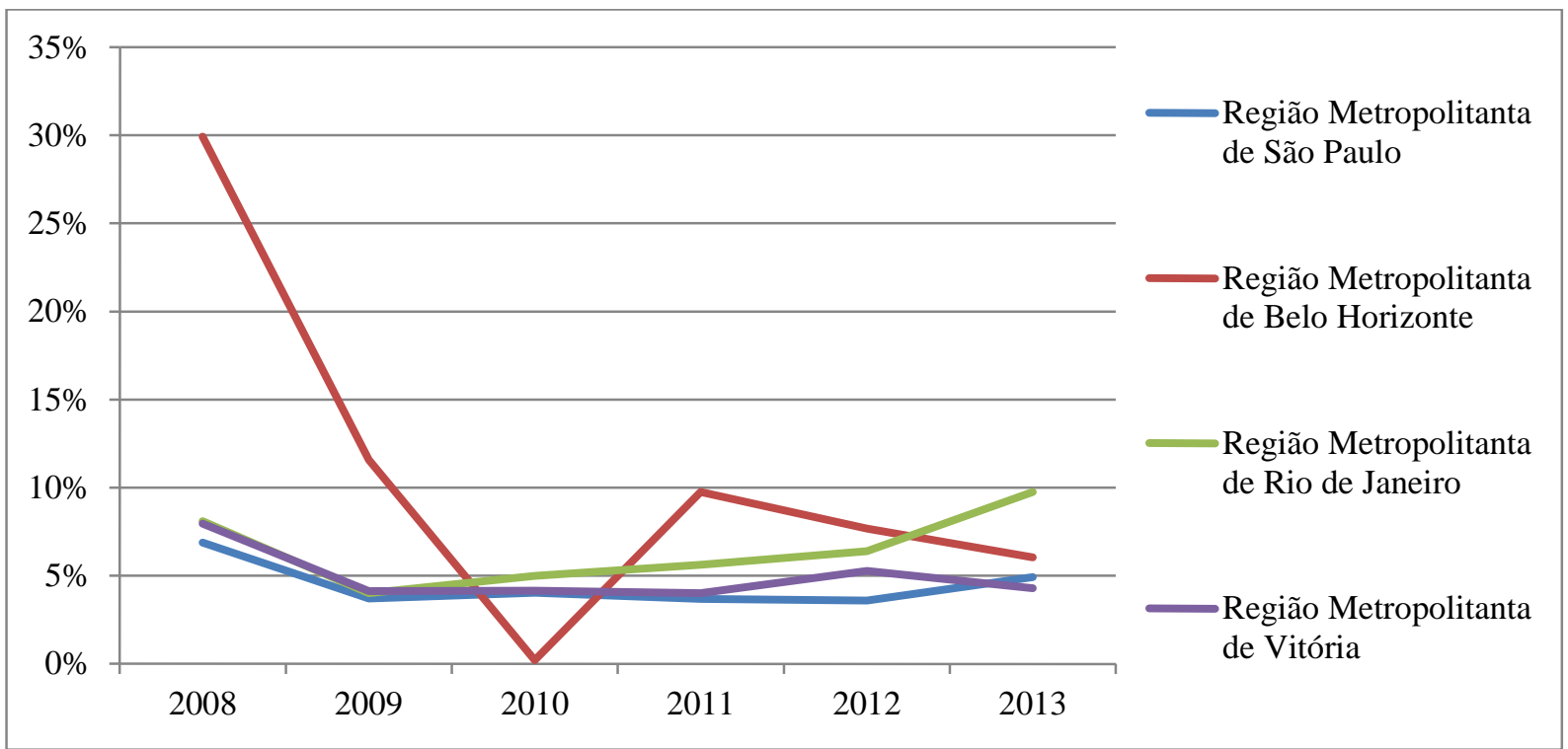

Fonte: Elaborado pelo autor

E a função Saneamento demonstrou similaridade nas regiões metropolitanas de São Paulo, Rio de Janeiro, Belo Horizonte e Vitória, ao início do período estudado, com a característica de redução da participação das despesas frente às receitas dos municípios que compõe essas regiões.

No final do lapso estudado foi averiguada similaridade entre as regiões de Rio de Janeiro e São Paulo, sendo essa o aumento da relação gasto social/receitas arrecadadas e recebidas de transferências de impostos. As regiões metropolitanas de Belo Horizonte e Vitória tiveram similaridade no sentido de apresentarem redução no índice.

Na comparação entre 2008 e 2013 averiguou que houve similaridade, sendo a redução para três regiões metropolitanas do sudeste do Brasil: São Paulo, Belo Horizonte e Vitória.

É importante salientar, e proceder a um estudo qualitativo que busque averiguar o que levou a esses resultados, principalmente, as relações que demonstraram diminuição das despesas frente ao total de receitas. A finalidade de proceder a essa forma de estudo é constatar se essas regiões tiveram eficácia, ou seja, cumpriram as exigências (prestação de bem-estar) da população, ou se fizeram um serviço "pela metade", que é a não prestação adequada do bem-estar aos munícipes.

\section{CONCLUSÃO}

Este estudo frisou em verificar a existência de similaridade entre os valores gastos com as funções sociais de Assistência Social, Previdência Social, Saúde, Educação, Cultura, 
Urbanismo, Habitação e Saneamento, no período de 2008 a 2013, confrontando com as receitas próprias e Receitas Transferidas de Impostos da (União e Estado), nas regiões metropolitanas do sudeste do Brasil.

Os resultados apresentaram que a função Assistência Social teve comportamento similar para as regiões metropolitanas de Belo Horizonte, Rio de Janeiro e Vitória, sendo representado pela redução da participação dos gastos sociais/receitas.

$\mathrm{Na}$ função Previdência Social ocorreu comportamento similar nas regiões metropolitanas de São Paulo, Belo Horizonte e Rio de Janeiro, sendo a característica a redução dos valores gastos com as despesas frente às receitas arrecadadas e transferidas.

A função Saúde demonstrou existir similaridade nas quatro regiões metropolitanas, cujo foco é a redução da relação despesas/receitas arrecadadas e transferidas.

$\mathrm{Na}$ função Educação averiguou similaridade de comportamento nas quatro regiões metropolitanas do sudeste brasileiro, e tendo como característica a redução da participação gastos sociais/receitas.

A função Cultura demonstrou a existência de um comportamento similar em todas as regiões estudadas, e a característica predominante foi a redução da relação despesas/receitas arrecadadas e transferidas.

Na função Urbanismo averiguou similaridade nas regiões metropolitana de São Paulo, Belo Horizonte e Vitória, sendo caracterizado pela diminuição de participação das despesas frente às receitas arrecadadas e transferidas.

A função Habitação apresentou similaridade nas regiões metropolitana de São Paulo e Rio de Janeiro, sendo a igualdade. Outra similaridade foi nas regiões metropolitana de Belo Horizonte e Vitória, e caracterizado pela redução da relação despesas/receitas.

E na função Saneamento ocorreu a similaridade nas cidades metropolitanas de São Paulo, Belo Horizonte e Vitória, tendo a característica de redução da participação das despesas frente às receitas dos municípios que compõe essas regiões.

É possível concluir que na maioria das funções sociais e nas cidades metropolitanas do sudeste do Brasil, existiu a diminuição dos gastos sociais em relação às receitas arrecadadas e recebidas em transferências.

Nesse sentido, é precípuo um estudo qualitativo que vise verificar se ocorreu um aumento acelerado das receitas ou se houve economia das despesas. Caso verifique a ocorrência de economia é importante constatar se existiu eficácia ou não, por parte dos gestores públicos, pois se eles tiverem conseguido realizar todas as atividades, prestando o 
bem estar a população está ótimo, mas caso não tenha conseguido é preciso proceder a uma mudança de atuação, para que a população não seja prejudicada.

\section{REFERÊNCIAS}

AGACHE, Alfred. Ed. Foyer Brésilien. Cidade do Rio de Janeiro, remodelação, extensão e embelezamento (Plano Agache). Rio de Janeiro, 1930.

ARAÚJO, Jair Andrade de; CAVALCANTE, Cristina Aragão; MONTEIRO, Vitor Borges. Influência dos Gastos Públicos no Crescimento Econômico dos Municípios do Ceará. In: VI Economia do Ceará em Debate 2010. Fortaleza: 2011, p. 176-200.

BACKES, Marli Terezinha Stein et al. Conceitos de saúde e doença ao longo da história sob o olhar epidemiológico e antropológico. Revista Enfermagem UERJ, Rio de Janeiro, v. 17, n. 1, p. 111-117, jan./mar. 2009.

BASTOS, Celso Ribeiro. Curso de Direito Financeiro e de Direito Tributário. 5. ed. São Paulo: Saraiva, 1997.

BORGES JUNIOR, Januário Rodrigues; MENDONÇA, Neire Divina. Contribuição de Melhoria. 2010. 16 f. Artigo (Especialização em Direito e Processo Tributário) - Pontifícia Universidade Católica de Goiás, Goiânia, 2010.

BOSCHETTI, I. SALVADOR, E. O financiamento da Seguridade Social no Brasil no período de 1999 a 2004: Quem paga a conta? In: Serviço Social e Saúde: Trabalho e Formação profissional. São Paulo: Cortez, 2006.

BOVO, José Murari. O conceito de capacidade de poupança própria na análise das finanças municipais. Revista de Administração Pública, Rio de Janeiro, v. 29, n. 1, p. 110-114, jan/mar. 1995.

BOVOLATO, Luís Eduardo. Saneamento Básico e Saúde. 2008.

BRASIL. Constituição Federal do Brasil de 1988. Constituição da República Federativa do Brasil. Poder Legislativo, Brasília, DF, 5 out. 1988. Seção 1, p. 1.

Lei $\mathrm{n}^{\circ}$ 5.172, de 25 de outubro de 1966. Dispõe sobre o Sistema Tributário Nacional e institui normas gerais de direito tributário aplicáveis à União, Estados e Municípios. Diário Oficial da União, Poder Executivo, Brasília, DF, 25 out. 1966. Seção 1, p. 12567.

Emenda Constitucional $\mathrm{n}^{\circ}$ 55, de 20 de setembro de 2007. Altera o art. 159 da Constituição Federal, aumentando a entrega de recursos pela União ao Fundo de Participação dos Municípios. Diário Oficial da União, Poder Legislativo, Brasília, DF, 21 de set. 2007. Seção 1, p. 1. 
CALLEJA, José Manuel Ruiz. Os professores deste século - algumas reflexões. Revista Institucional Universidad Tecnológica del Chocó: Investigation, Biodiversidad y Desarrollo, v. 27, n. 1, p. 109-117, 2008.

CANEDO, Daniele. “Cultura é o quê?” - reflexões sobre o conceito de cultura e a atuação dos poderes públicos. In: ENECULT - Encontro de Estudos Multidisciplinares em Cultura., 5., 2009, Salvador, Anais.... Salvador: Faculdade de Comunicação - UFBA, 2009.

CARVALHO SANTOS, José Lázaro de. Reflexões por um conceito contemporâneo de urbanismo. Disponível em: <http://sburbanismo.vilabol.uol.com.br>. Acesso em: 25 nov. 2014.

DOURADO, Luiz Fernandes; OLIVEIRA, João Ferreira de; SANTOS, Catarina de Almeida. A qualidade da educação: conceitos e definições. Ministério da Educação - Instituto Nacional de Estudos e Pesquisas Educacionais Anísio Teixeira, Brasília, v. 24, n. 22, p. 0534, 2007.

FERNANDES, Maria Alice da Cunha et al. Dimensionamento e Acompanhamento do Gasto Social Federal. IPEA, fev. 1998.

GUIMARÃES, A. J. A.; CARVALHO, D. F. de; SILVA, L. D. B. Saneamento básico. Disponível em:

<http://www.ufrrj.br/institutos/it/deng/leonardo/downloads/APOSTILA/Apostila\%20IT\%201 79/Cap\%201.pdf>. Acesso em: 15 dez. 2014.

HARADA, Kiyoshi. Direito Financeiro e Tributário. 21. ed. São Paulo: Atlas, 2012.

INSTITUTO BRASILEIRO DE GEOGRÁFIA ESTATÍSTICA. Região Sudeste. 2014.

JOCOB, Cesar Romero; HEES, Dora Rodrigues; WANIEZ, Philippe. Atlas das condições de vida na Região Metropolitana do Rio de Janeiro. Rio de Janeiro: PUC-Rio, 2014.

KOHAMA, Heilio. Contabilidade pública: teoria e prática. 8. ed. São Paulo: Atlas, 2001.

MACHADO JUNIOR, José Teixeira; REIS, Heraldo da Costa. A Lei 4.320 comentada. 27. ed. Rio de Janeiro: Ibam, 1996

MALPASS, P. Housing and the new Welfare State. Conference Transforming Social Housing. Sheffield: Hallam University, HSA Abril, 2004.

MARWELL, Tatiana Eulálio D. G. A natureza jurídica do empréstimo compulsório. Caderno de Estudos Ciência e empresa, Teresina, v. 5, p. 2, 2008.

MONTEIRO, Doraliza Auxiliadora Abranches et al. Gastos Sociais e Transferência de Renda no Brasil: Reflexões sobre o Programa Bolsa Família. In: Marco Aurélio Marques Ferreira; Magnus Luiz Emmendoerfer; Rodrigo Gava. (Org.). Administração pública, gestão social e economia solidária: avanços e desafios. Viçosa: UFV, 2010, v. 1, p. 5-25. 2010. 
MINISTÉRIO da Fazenda. Gasto Social do Governo Central: 2001 e 2002. Brasília, 2003. Disponível em: < http://www.fedepsp.org.br/superior/gasto_social_01_02.pdf >. Acesso em: 20 out. 2014.

NASCIMENTO, Edson Ronaldo. Gestão Pública. São Paulo: Saraiva, 2006.

PALADINI, Alison Pinton. Entraves à Efetividade da Contribuição de Melhoria. Artigo Científico (Especialização em Jurisdição Federal). Programa de Pós-graduação pela Escola Superior da Magistratura Federal do Estado de Santa Catarina, Santa Catarina, 2012.

RANGEL, Leonardo Alves et al. Conquistas, Desafios e Perspectivas da Previdência Social no Brasil vinte anos após a promulgação da Constituição Federal de 1988. In: Previdência Social. Brasília, 2009.

SANT'ANNA, José Mário Bispo. Efeito do gasto público sobre o PIB: um teste empírico nos municípios do estado do Espírito Santo. Dissertação (Mestrado em Ciências Contábeis). Programa de Pós-Graduação em Ciências Contábeis da Fundação Instituto Capixaba de Pesquisa em Contabilidade, Economia e Finanças (FUCAPE), Vitória, 2006.

SANTOS, Luciana Batista. Contribuição de melhoria: um tributo esquecido. Revista do Centro Acadêmico Afonso Pena, Belo Horizonte, v. 1, n. 1, 1998, p. 147.

SANTOS, Geovane Camilo dos; ANDRADE, Sandro Ângelo de. Influência dos gastos sociais sobre o PIB dos municípios da região oeste do Estado de Minas Gerais. Revista Perquirere, Patos de Minas, v. 2, n. 9, p. 218-232, 2012.

Análise da aplicação de recursos públicos em gastos sociais nas cidades pólos de Minas Gerais. Revista Pensar Contábil, Rio de Janeiro, v. 18, n. 60, p. 14-22, 2014.

SANTOS, Geovane Camilo dos; OLIVEIRA, Maria Auxiliadora Godinho de; TRAJANO JÚNIOR, Edvard. O que é mais vantajoso para o município de Patos de Minas manter próprio ou terceirizar o transporte público escolar rural? Um estudo de caso. In:CONGRESSO BRASILEIRO DE CUSTOS, 20.,2013, Uberlândia. Anais... São Leopoldo: Associação Brasileira de Custos, 2013.

SCLIAR, Moacyr. História do Conceito de Saúde. PHYSIS: Revista Saúde Coletiva, Rio de Janeiro, v. 17, n. 1, p. 29-41, 2007.

SECRETARIA DO TESOURO DA FAZENDA. Receitas públicas: manual de procedimentos - aplicado à União, Estados, Distrito Federal e Municípios. 3. ed. Brasília: Secretaria. do Tesouro Nacional, Coordenação-Geral de Contabilidade, 2006.

SECRETARIA DO ESTADO DA FAZENDA DE MATO GROSSO. Transferências Constitucionais. Mato Grosso, 2014.

SILVA, Ana Lúcia Guimarães; MARTINS, Floriano José; COSTA, Rosânia. Cartilha Benefícios Previdência Social. Brasília: Fundação ANFIP de Estudos da Seguridade Social, 2014. 
SLOMSKI, Valmor; SCARPIN, Jorge Eduardo. Estudo dos fatores condicionantes do Índice de Desenvolvimento Humano nos municípios do estado do Paraná:instrumento de controladoria para a tomada de decisões na gestão governamental. Disponível em: <http://www.congressousp.fipecafi.org/artigos62006/193.pdf>. Acesso em: 4 dez. 2014.

SOARES, Maurélio; GOMES, Ely do Carmo Oliveira; TOLEDO FILHO, Jorge Ribeiro de.A repartição tributária dos recursos do ICMS nos municípios da Região Metropolitana de Curitiba. Revista de Administração Pública, Rio de Janeiro, v. 45, n. 2, p. 459-481, mar/abr. 2011.

SPOSATI, Aldaíza. Assistência Social: de Ação Individual a Direito Social. Revista Brasileira de Direito Constitucional - RBDC, São Paulo, n. 10, jul./dez. 2007.

SOUZA, Charles Okama; OLIVIERA FILHO, Ariane de; FREITAS, Bruna Rodrigues de. Destinação de recursos nos municípios da Zona da Mata de Minas Gerais: uma avaliação das despesas orçamentárias. In: CONGRESSO BRASILEIRO DE CUSTOS, 18., 2011, Rio de Janeiro. Anais.... São Leopoldo: Associação Brasileira de Custos, 2011. CD ROM. 